\title{
Calix[4]pyridine: a new arrival in the heterocalixarene family
}

\author{
Vladimír Král, ${ }^{a, b}$ Philip A. Gale, ${ }^{a}$ Pavel Anzenbacher Jr., ${ }^{a, b}$ Karolina Jursíková, ${ }^{a}$ Vincent Lynch ${ }^{a}$ and \\ Jonathan L. Sessler*a \\ a Department of Chemistry and Biochemistry, The University of Texas at Austin, Austin, Texas, 78712-1167, USA \\ ${ }^{b}$ Institute of Chemical Technology, Department of Analytical Chemistry, Prague, 16628 Czech Republic
}

Reaction of dichlorocarbene with meso-octamethylcalix[4]pyrrole causes pyrrole ring expansion, producing chlorocalixpyridinopyrroles and chlorocalixpyridines.

Considerable effort of late has been devoted to synthesizing new macrocycles containing pyridine subunits. While many such systems have been reported, some of considerable elegance, ${ }^{1}$ one of the simplest conceivable pyridine-containing macrocycles, calix[4]pyridine, remains unknown.

Currently, close analogues of calix[4]pyridine, in the form of homocalixpyridines ${ }^{2}$ and tetrapyridine tetraone ${ }^{3}$ macrocycles are known. However, macrocyclic systems with pyridine rings linked in the 2 and 6 positions via a single $\mathrm{sp}^{3}$ hybridized carbon atom have yet to be prepared. We have now discovered a general synthetic strategy that not only allows for the preparation of calix[4]pyridine derivatives (e.g. 1), but also provides access to calix $[n]$ pyridino $[n]$ pyrroles $(m+n=4)$. While some species related to this latter set of macrocycles are known, namely mixed porphyrin-like pyrrole-pyridine systems and calixpyridinopyrroles containing one or two pyridines, ${ }^{4}$ calix[3]pyridine[1]pyrrole derivatives (e.g. 4), as reported here, appear to be without precedent in the literature.

Our initial synthetic efforts were based on attempts to condense substituted pyridine $N$-oxides in a manner analogous to $p$-tert-butylphenol in calixarene synthesis..$^{5}$ However none of the desired products could be isolated from the reaction mixtures. Our attention then turned on finding methods that would allow us to convert calix[4]pyrroles ${ }^{6}$ (e.g. 5) to calix[4]pyridines. Reaction of dichlorocarbene with pyrrole, imidazole or indole rings has been shown to cause an insertion of the $\mathrm{CCl}_{2}$ unit into one of the double bonds. ${ }^{7}$ In the case of pyrroles, subsequent elimination of $\mathrm{HCl}$ and rearrangement produces a 3-chloropyridine ring. We thus attempted the conversion of meso-octamethylcalix[4]pyrrole $\mathbf{5}$ into tetrachloro-meso-octamethylcalix[4]pyridine $\mathbf{1}$ in several different solvents using a range of reaction times as well as different (excess) concentrations of sodium trichloroacetate. Using dioxane as the solvent, and 15 equiv. of sodium trichloroacetate, a 2.4:1 mixture of the mono- and di-pyridine macrocycles (2 and 3) was formed. Interestingly when the same reaction conditions were employed using 1,2-dimethoxyethane as solvent, a mixture of di-, tri- and tetra-pyridine species $3, \mathbf{4}$ and $\mathbf{1}$ was obtained in a $1: 1: 1$ ratio (Scheme 1). $\dagger$ The latter conditions, therefore, offer easy access to chlorinated derivatives of two previously unknown macrocycles, namely, calix[3]pyridino[1]pyrrole $\mathbf{4}$ and calix[4]pyridine 1, in the same reaction. In any event, it was found that by adding between 3 and 6 equiv. of the carbene source in a sequential manner, isolated yields of 65,42 and $26 \%$ could be obtained for targets 3,4 and $\mathbf{1}$, respectively.

$\mathrm{X}$-Ray diffraction-grade single crystals of compound $\mathbf{3}$ were grown by slow evaporation of a dilute $\mathrm{CH}_{2} \mathrm{Cl}_{2}$ solution of the macrocycle (Fig. 1) $\ddagger$ The resulting X-ray structure reveals that there are two crystallographically distinct molecules in the unit cell. Both adopt the cone conformation in the solid state such that potential $\mathrm{NH} \cdots \mathrm{N}$ hydrogen bonds are formed. These hydrogen bonds may influence the conformation of the macrocycle.

Crystals of the calix[3]pyridino[1]pyrrole were grown from a $\mathrm{MeOH}-\mathrm{CH}_{2} \mathrm{Cl}_{2}$-hexanes solvent mixture. $\S \mathrm{As}$ in the structure
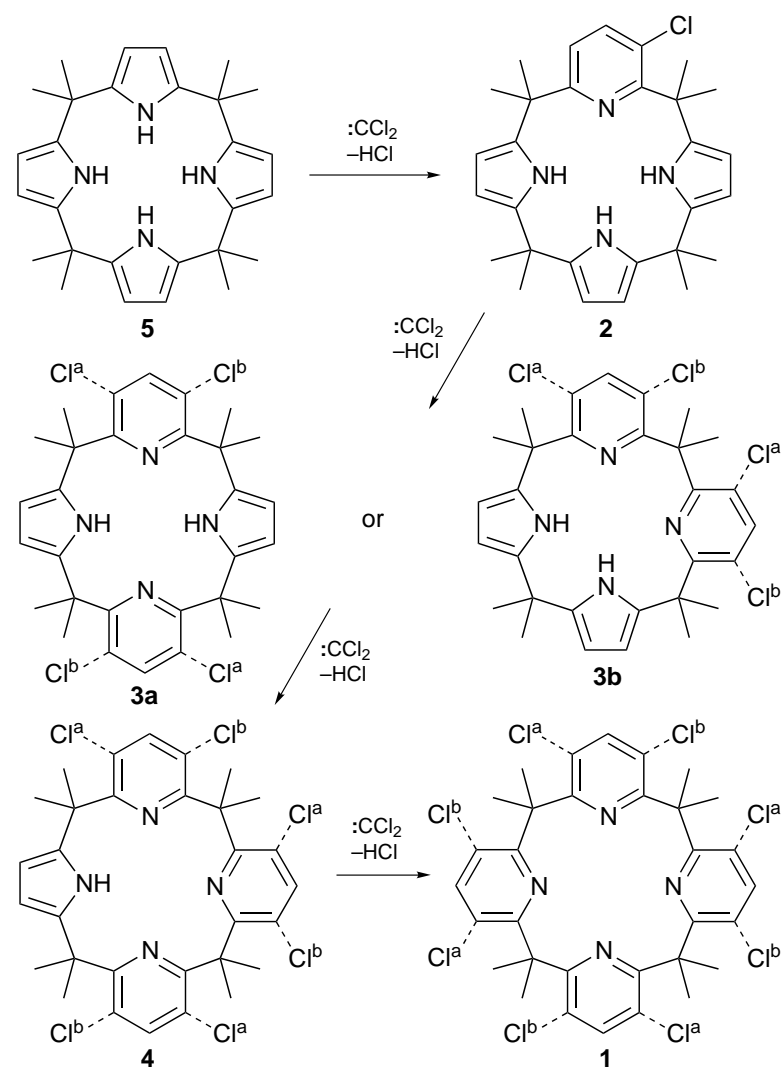

Scheme 1 The chlorine atoms indicated may be present in position ' $a$ ' or ' $b$ ' but not both. This results in isomers, as discussed in the text.

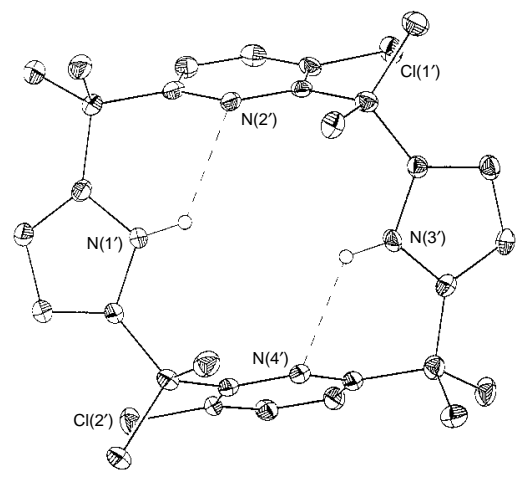

Fig. 1 X-Ray crystal structure of 3. Intramolecular hydrogen bonds are shown by dotted lines. Thermal ellipsoids are at the $30 \%$ probability level. 


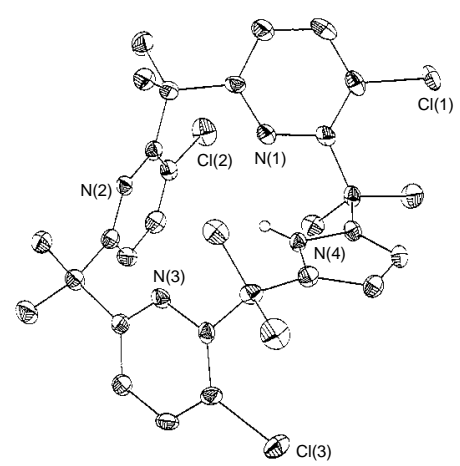

Fig. 2 X-Ray crystal structure of 4 . Only one molecule from the asymmetric unit is shown. Thermal ellipsoids are at the $30 \%$ probability level.

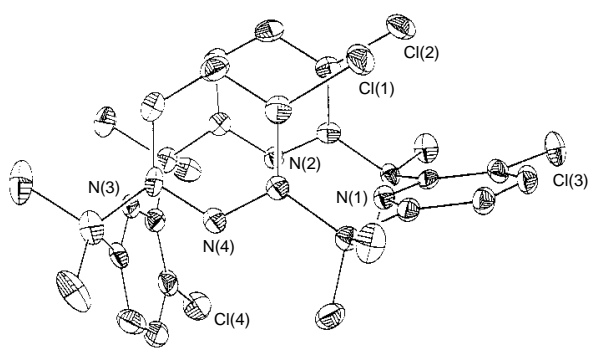

Fig. 3 X-Ray crystal structure of $\mathbf{1}$. Intramolecular hydrogen bonds are shown by dotted lines. Thermal ellipsoids are at the $30 \%$ probability level.

of compound $\mathbf{3}$, there are two molecules of compound $\mathbf{4}$ per asymmetric unit. The two molecules in the structure of $\mathbf{4}$ assume strikingly different conformations. For molecule 2, the molecular conformation is similar to that found in the structure of $\mathbf{1}$ (below) where alternate rings are either nearly parallel or nearly perpendicular. The dihedral angle between ring 2 (as denoted by the nitrogen atom label) and the pyrrole ring 4 is $81.9(2)^{\circ}$. The dihedral angle between ring 1 and ring 3 is $13.4(2)^{\circ}$. The dihedral angles between the rings and the plane through the bridging carbon atoms $\mathrm{C}\left(6^{\prime}\right), \mathrm{C}\left(12^{\prime}\right), \mathrm{C}\left(18^{\prime}\right)$ and $\mathrm{C}\left(23^{\prime}\right)$ is $81.6(2)^{\circ}$ for ring $1,74.9(2)^{\circ}$ for ring $2,85.1(2)^{\circ}$ for ring 3 and $7.3(3)^{\circ}$ for ring 4 . Molecule 1 has a dramatically different conformation (Fig. 2). The dihedral angles between the rings and the plane through the bridging carbon atoms of molecule 1 are $51.3(2)^{\circ}$ for ring $1,89.3(2)^{\circ}$ for ring $2,55.5(2)^{\circ}$ for ring 3 and $21.5(2)^{\circ}$ for ring 4 .

Single crystals of the calix[4]pyridine 1 were grown by slow evaporation of a $\mathrm{CH}_{2} \mathrm{Cl}_{2}$-hexane-MeOH solution of the macrocycle (Fig. 3).II The molecule adopts a flattened partial cone conformation in the solid state.

In summary, we have developed a universal and easy synthetic protocol for the preparation of calix $[\mathrm{m}]$ pyridino$[n]$ pyrrole $(m+n=4)$ and calix[4]pyridine systems based on a non-metal mediated ring expansion of pyrrole. We are currently investigating the molecular recognition properties of these new systems.

This research was supported by the National Institutes of Health (grants AI 33577 to J. L. S., and TW00682 to J. L. S. and V. K.), the National Science Foundation (grant CHE 9725399 to J. L. S) and the Howard Hughes Medical Institute (J. L. S. and V. K.). P. A. G. wishes to thank the Fulbright Commission for a post-doctoral research scholarship.

\section{Footnotes and References}

* E-mail: sessler@mail.utexas.edu

$\dagger$ Isomers are present in the reaction mixture, since the intermediate dichlorocarbene formed can insert into either of the two double bonds present in each of the various pyrrole rings under attack.

$\ddagger$ Crystal data for 3: Colourless plates of $\left(\mathrm{C}_{30} \mathrm{H}_{34} \mathrm{~N}_{4} \mathrm{Cl}_{2}\right)_{2} \cdot \mathrm{CH}_{2} \mathrm{Cl}_{2}$; triclinic, space group $P \overline{1}$, with $a=12.546(2), b=15.403(2), c=16.771(3) \AA$, $\alpha=63.95(11), \beta=82.953(10), \gamma=76.937(9)^{\circ}, V=2835.3(8) \AA^{3}$, $Z=2, \mu=3.51 \mathrm{~cm}^{-1}, \rho_{\text {calc }}=1.32 \mathrm{~g} \mathrm{~cm}^{-3}, M=1127.95$. There are two molecules of $\mathrm{C}_{30} \mathrm{H}_{34} \mathrm{~N}_{4} \mathrm{Cl}_{2}$ along with a partially disordered $\mathrm{CH}_{2} \mathrm{Cl}_{2}$ solvate molecule per asymmetric unit. The conformations of the two macrocycles are nearly identical. The final $R_{\mathrm{w}}\left(F^{2}\right)=0.215$ with a goodness of fit $=1.071$, while the conventional $R(F)=0.0844$ for 5852 reflections with $F_{\mathrm{o}}>4\left[\sigma\left(F_{\mathrm{o}}\right]\right.$.

$\$$ Crystal data for 4: Colourless needle-shaped crystals of $\left(\mathrm{C}_{31} \mathrm{H}_{33} \mathrm{~N}_{4} \mathrm{Cl}_{3}\right)_{2} \cdot 0.5 \mathrm{CH}_{2} \mathrm{Cl}_{2}$ were monoclinic, space group $P 2_{1} / c$, with $a=$ 28.646(5), $b=10.368(2), c=19.877(3) \AA, \beta=93.76(1)^{\circ}, V=5891(2)$ $\AA^{3}, Z=4, \mu=3.85 \mathrm{~cm}^{-1}, \rho_{\text {calc }}=1.33 \mathrm{~g} \mathrm{~cm}^{-3}, M=1178.39$. The pyrrolic hydrogen atoms were refined. There are two crystallographically independent molecules per asymmetric unit. The two molecules have markedly different conformations. There is a small amount of disorder of some $\mathrm{Cl}$ atoms on the pyridine rings in both molecules. The $\mathrm{CH}_{2} \mathrm{Cl}_{2}$ solvate molecule is disordered about a crystallographic inversion centre. The final $R_{\mathrm{w}}\left(F^{2}\right)$ $=0.191$ with a goodness of fit $=1.004$, while the conventional $R(F)=0.0774$ for 5037 reflections with $F_{\mathrm{o}}>4\left[\sigma\left(F_{\mathrm{o}}\right)\right]$.

II Crystal data for 1: Colourless needle-shaped crystals of $\mathrm{C}_{32} \mathrm{H}_{32} \mathrm{~N}_{4} \mathrm{Cl}_{4}$ were triclinic, space group $P \overline{1}$, with $a=9.883(2), b=10.159(2)$, $c=15.720(3) \AA, \alpha=93.66(2), \beta=104.89(2), \gamma=98.92(1)^{\circ}$, $V=1498.0(5) \AA^{3}, Z=2, \mu=4.24 \mathrm{~cm}^{-1}, \rho_{\text {calc }}=1.36 \mathrm{~g} \mathrm{~cm}^{-3}$, $M=614.42$. The chlorine atoms, $\mathrm{Cl}(3)$ and $\mathrm{Cl}(4)$, appear to be disordered about two orientations. partial occupancy chlorine atoms appear bound to $\mathrm{C}(2)$ and $\mathrm{C}(16)$. The final $R_{\mathrm{w}}\left(F^{2}\right)=0.184$ with a goodness of fit $=1.049$, while the conventional $R(F)=0.0750$ for 2440 reflections with $F_{\mathrm{o}}>$ $4\left[\sigma\left(F_{\mathrm{o}}\right)\right] .182 / 654$.

1 For an early review of pyridine containing macrocycles (along with furan and thiophene) see G. R. Newkome, J. D. Sauer, J. M. Roper and D. C. Hager, Chem. Rev., 1977, 77, 513. Mixed porphyrin-like pyrrolepyridine systems are also known; see for instance T. D. Lash and S. T. Chaney, Chem. Eur. J., 1996, 2, 944; T. Schönemeier and E. Breitmaier, Synthesis, 1977, 273. For dodecahydrohexaazakekulene synthesis, see H. A. Staab and F. Diederich, Chem. Ber., 1983, 116, 3487 H. A. Staab, F. Diederich, C. Krieger and D. Schweitzer, Chem. Ber., 1983, 116, 3504. For the synthesis of sexipyridines, see J. L. Toner, Tetrahedron Lett., 1983, 24, 2707; G. R. Newkome and H.-W. Lee, J. Am. Chem. Soc., 1983, 105, 5956

2 For a review of homocalixarenes and homocalixpyridines, see G. Brodesser and F. Vögtle, J. Inclusion Phenom., 1994, 19, 111.

3 G. R. Newkome, Y. J. Joo and F. R. Fronczek, J. Chem. Soc., Chem. Commun., 1987, 854.

4 D. Jacoby, S. Isoz, C. Floriani, A. Chiesi-Villa and C. Rizzoli, J. Am. Chem. Soc., 1995, 117, 2793.

5 C. D. Gutsche and M. Iqbal, Org. Synth., 1990, 68, 234.

6 A. Bayer, Ber. Dtsch. Chem. Ges., 1886, 19, 2184; D. Jacoby, C. Floriani, A. Chiesi-Villa and C. Rizzoli, J. Chem. Soc., Chem. Commun., 1991, 220; P. A. Gale, J. L. Sessler, V. Král and V. Lynch, J. Am. Chem. Soc., 1996, 118, 5140; P. A. Gale, J. L. Sessler, V. Lynch and P. I. Sansom, Tetrahedron Lett., 1996, 37, 7881; W. E. Allen, P. A. Gale, C. T. Brown, V. M. Lynch and J. L. Sessler, J. Am. Chem. Soc., 1995, 118, 12471; J. L. Sessler, A. Andrievsky, P. A. Gale and V. Lynch, Angew. Chem., Int. Ed. Engl., 1996, 35, 2782; P. A. Gale, J. L. Sessler, W. E. Allen, N. A. Tvermoes and V. Lynch, Chem. Commun., 1997, 665.

7 C. W. Rees and C. E. Smithen, J. Chem. Soc., 1964, 928; C. W. Rees and C. E. Smithen, J. Chem. Soc., 1964, 938; R. L. Jones and C. W. Rees, J. Chem. Soc. (C), 1969, 2249; R. L. Jones and C. W. Rees, J. Chem. Soc. (C), 1969, 2251; R. L. Jones and C. W. Rees, J. Chem. Soc. (C), 1969, 2255 .

Received in Columbia, MO, USA, 18th August 1997; 7/06018A 